\title{
Effects of donepezil on cognitive functions and the expression level of $\beta$-amyloid in peripheral blood of patients with Alzheimer's disease
}

\author{
YUNXIA MA, JINMING JI, GANG LI, SHUZHEN YANG and SHUANGSHUANG PAN \\ Department of Neurology, Binzhou City Center Hospital, Binzhou, Shandong 251700, P.R. China
}

Received July 7, 2017; Accepted November 15, 2017

DOI: $10.3892 /$ etm.2017.5613

\begin{abstract}
Alzheimer's disease is a degenerative disease affecting the central nervous system for which donepezil is usually prescribed. The aim of the present study was to examine the effects of donepezil on the cognitive functions and expression levels of $\beta$-amyloid $(\mathrm{A} \beta)$ in the peripheral blood of patients with Alzheimer's disease. In total, 76 patients with cognitive impairment, who visited the Department of Neurology of Binzhou City Center Hospital from June 2015 to September 2016, had memory decline for more than three consecutive months and underwent mini-mental state examination (MMSE) score screening, were selected for the study. All 76 patients were divided into the experimental $(n=38)$ and control $(n=38)$ groups by random number table. Patients in the control group were treated using conventional drugs combined with Nimotop, and patients in the experimental group received conventional drug therapy combined with donepezil, and the treatment outcomes in the two groups were compared. The MMSE scores and Montreal cognitive assessment (MoCA) scores after treatment in the two groups were significantly increased compared with those before treatment, and the differences were statistically significant $(\mathrm{P}<0.05)$. The activities of daily living scale (ADL) was decreased significantly $(\mathrm{P}<0.05)$. By comparing with the control group, the MMSE and MoCA scores in the experimental group were higher $(\mathrm{P}<0.05)$ while the ADL score was lower $(\mathrm{P}<0.05)$, and the adverse reaction rate during the treatment was lower $(\mathrm{P}<0.05)$. The $\mathrm{A} \beta$ levels in serum after medical treatment were obviously decreased in the two groups, and the difference was statistically significant $(\mathrm{P}<0.05)$. The serum $A \beta$ level in the experimental group after treatment was lower than that in the control group $(\mathrm{P}<0.05)$. Drug therapy combined with donepezil has a certain degree of influence on the MMSE, ADL and MoCA scores of patients
\end{abstract}

Correspondence to: Dr Yunxia Ma, Department of Neurology, Binzhou City Center Hospital, 108 Huangchengnan Road, Huimin, Binzhou, Shandong 251700, P.R. China

E-mail: xunxiama@163.com

Key words: Alzheimer's disease, donepezil, cognitive functions, A $\beta$ in peripheral blood with Alzheimer's disease, which can decrease the $A \beta$ level in peripheral blood and improve the cognitive functions of patients, thus having important clinical significance.

\section{Introduction}

Alzheimer's disease, commonly known as 'senile dementia', is a degenerative disease of the central nervous system with insidious onset and long course, of which the main clinical symptoms are language disorder, cognitive impairment, memory impairment and abnormal behavior; thus, severely influencing the patients' quality of life (1).

The pathogenesis of Alzheimer's disease remains unknown, but $\beta$-amyloid $(\mathrm{A} \beta)$ in peripheral blood plays an important role in the onset of the disease (2). The drug donepezil has a long-term therapeutic effect on Alzheimer's disease and can ameliorate the cognitive ability of the patients, which has been recognized by the medical community.

Therefore, the present study observed and analyzed the effects of donepezil in the treatment of Alzheimer's disease and detected the $\mathrm{A} \beta$ level in serum in order to provide a reference to clinical treatment.

\section{Materials and methods}

General information. Seventy-six patients with cognitive impairment, who visited the Department of Neurology of Binzhou City Center Hospital from June 2015 to September 2016, and had memory decline for more than three consecutive months and underwent mini-mental state examination (MMSE) screening, were selected. Patients received examinations and conformed to the diagnostic criteria for Alzheimer's disease defined in the Diagnostic and Statistical Manual of Mental Disorders (edition IV) published by the American Psychiatric Association (3). Patients with disturbance of consciousness, depression, cardiovascular diseases, dysfunction of liver and kidney, and drug allergy were excluded.

The study was approved by the Ethics Committee of Binzhou City Center Hospital and signed informed consent was obtained from the patients.

The patients were divided into the experimental $(n=38)$ and control $(n=38)$ groups by random number table. In the experimental group, there were 20 men and 18 women, aged 62-87 years, with an average age of $71.34 \pm 6.77$ years. The 
Table I. Comparisons of MMSE, ADL and MoCA scores before and after treatment in the two groups.

\begin{tabular}{|c|c|c|c|c|c|}
\hline Group & Index & Before treatment & After treatment & t-value & P-value \\
\hline Experimental group $(\mathrm{n}=38)$ & MMSE score & $16.28 \pm 2.08$ & $24.23 \pm 1.86$ & 17.530 & $<0.001$ \\
\hline Control group $(\mathrm{n}=38)$ & MMSE score & $16.33 \pm 2.14$ & $20.82 \pm 2.05$ & 10.897 & $<0.001$ \\
\hline t-value & & 0.103 & 6.571 & & \\
\hline $\mathrm{P}$-value & & 0.918 & $<0.001$ & & \\
\hline Experimental group $(n=38)$ & ADL score & $43.37 \pm 3.42$ & $25.62 \pm 4.59$ & 22.648 & $<0.001$ \\
\hline Control group $(n=38)$ & ADL score & $42.81 \pm 3.92$ & $31.13 \pm 4.07$ & 14.099 & $<0.001$ \\
\hline t-value & & 0.549 & 6.583 & & \\
\hline P-value & & 0.584 & $<0.001$ & & \\
\hline Experimental group $(\mathrm{n}=38)$ & MoCA score & $15.27 \pm 1.86$ & $24.31 \pm 1.56$ & 21.528 & $<0.001$ \\
\hline Control group $(n=38)$ & MoCA score & $15.11 \pm 1.67$ & $20.14 \pm 1.43$ & 12.059 & $<0.001$ \\
\hline t-value & & 0.394 & 9.864 & & \\
\hline P-value & & 0.694 & $<0.001$ & & \\
\hline
\end{tabular}

Table II. Comparisons of serum A $\beta$ levels before and after treatment in the two groups.

\begin{tabular}{lccr}
\hline Group & Before treatment & After treatment & t-value \\
\hline Experimental group $(\mathrm{n}=38)$ & $12.91 \pm 3.08$ & $4.18 \pm 1.13$ & 16.403 \\
Control group $(\mathrm{n}=38)$ & $12.88 \pm 3.12$ & $7.07 \pm 1.81$ & 10.077 \\
t-value & 0.042 & 8.349 & $<0.001$ \\
P-value & 0.967 & $<0.001$ & \\
\hline
\end{tabular}

duration of disease was 2-8 years, with an average duration of $5.72 \pm 2.34$ years. In the control group, there were 21 men and 17 women aged 60-88 years, with an average age of $72.864 \pm 6.69$ years. The duration of disease was $2-8$ years, with an average duration of $5.97 \pm 2.22$ years. There were no notable differences in sex, age, duration of disease and other general information between the two groups of patients, which was not statistically significant but comparable $(\mathrm{P}>0.05)$.

Methods. Patients in the two groups received conventional treatment. The control group was further treated by Nimotop (Bayer HealthCare LLC., NMPN 20003010; specification: $30 \mathrm{mg}$ x 20 tablets/box), with 1 tablet being administered orally twice a day for 6 consecutive months. The experimental group was administered donepezil on the basis of conventional treatment. Thus, 1 tablet of donepezil [Eisai China Pharmaceutical Co., Ltd. (Shanghai, China) NMPN H20050978; specification: 5 mg x 7 tablets] was administered once daily orally for 6 consecutive months, and the dosage was increased 4 weeks later.

Observation indexes. Patients in the two groups were treated for 6 consecutive months, and the scores of MMSE, activities of daily living scale (ADL) and Montreal cognitive assessment (MoCA) as well as adverse reaction rates of the two groups were assessed. Venous blood $(5 \mathrm{ml})$ in the two groups was collected before and after treatment, and indirect enzyme-linked immunosorbent assay (ELISA) was used to measure the changes of serum $A \beta$ levels before and after treatment. Mouse anti-human $\mathrm{A} \beta$ monoclonal antibodies and kits were purchased from Sigma (St. Louis, MO, USA) (4).

Statistical analysis. Statistical Product and Service Solutions (SPSS) 22.0 (IBM Co., Armonk, NY, USA) was used for statistical analysis. Measurement data were presented as mean \pm SD. The t-test was performed for comparisons between groups, and enumeration data were presented as a percentage, and the Chi-square test was applied to comparisons between groups. The paired t-test was used for comparisons before and after treatment within the group. $\mathrm{P}<0.05$ was considered to indicate a statistically significant difference.

\section{Results}

Comparisons of MMSE, ADL and MoCA scores before and after treatment in the two groups. The MMSE and MoCA scores after treatment in both groups were significantly increased compared with those before treatment, and the differences were statistically significant $(\mathrm{P}<0.05)$. The ADL score was decreased significantly $(\mathrm{P}<0.05)$. Compared with the control group, the MMSE and MoCA scores in the experimental group were higher $(\mathrm{P}<0.05)$ while the ADL score was decreased $(\mathrm{P}<0.05)$ (Table I).

Comparisons of serum A $\beta$ levels before and after treatment in the two groups. In the experimental group, the serum $\mathrm{A} \beta$ 
Table III. Comparisons of adverse reaction rates in the two groups.

\begin{tabular}{lcccccc}
\hline Group & Nausea & Vomiting & Diarrhea & Dizziness & Inappetence & Incidence \\
\hline Experimental group $(\mathrm{n}=38)$ & $1(2.63 \%)$ & $1(2.63 \%)$ & $1(2.63 \%)$ & $2(5.26 \%)$ & $0(0 \%)$ & $5(13.17 \%)$ \\
Control group $(\mathrm{n}=38)$ & $2(5.26 \%)$ & $2(5.26 \%)$ & $1(2.63 \%)$ & $4(10.52 \%)$ & $1(2.63 \%)$ & $10(26.31 \%)$ \\
$\chi^{2}$ value & & & & & & 6.294 \\
P-value & & & & & 0.012 \\
\hline
\end{tabular}

levels before and after treatment were $12.91 \pm 3.08 \mathrm{pg} / \mathrm{ml}$ and $4.18 \pm 1.13 \mathrm{pg} / \mathrm{ml}$, respectively. In the control group, the serum $\mathrm{A} \beta$ levels before and after treatment were $12.88 \pm 3.12 \mathrm{pg} /$ $\mathrm{ml}$ and $7.07 \pm 1.81 \mathrm{pg} / \mathrm{ml}$, respectively. The difference in the serum $A \beta$ levels before treatment between the two groups was not notable, and thus not statistically significant $(\mathrm{P}>0.05)$. After medical treatment, the $A \beta$ levels in serum were obviously decreased in the two groups, and the difference was statistically significant $(\mathrm{P}<0.05)$. The serum $A \beta$ level in the experimental group after treatment was lower than that in the control group $(\mathrm{P}<0.05)$ (Table II).

Comparisons of adverse reaction rates in the two groups. The adverse reaction rate in the experimental group (13.17\%) was obviously lower than that in the control group (26.31\%), and the difference between the two groups was statistically significant $(\mathrm{P}<0.05)$ (Table III).

\section{Discussion}

With the accelerated aging process in China, the prevalence of Alzheimer's disease shows an annual rising trend. As a type of dementia, Alzheimer's disease is a degenerative disease of the nervous system, accompanied by special physiological and pathological changes, with senile plaque and neurofibrillary tangle as its main pathological characteristics (5). The loss of cholinergic neurons, as well as decreased cholinergic activity in cortex, hippocampus, striatum and cerebrospinal fluid in the patients with Alzheimer's disease can lead to impairment in cognitive functions and memory of the patients, and finally loss of self-care ability, leading to serious economic burden to their family and society $(6,7)$. The mechanism of Alzheimer's disease has not been fully understood in clinical practice thus far. Pathological characteristics mainly include senile plaque outside the nerve cells formed by $\mathrm{A} \beta$, neurofibrillary tangle inside the nerve cells formed by hyperphosphorylated $\tau$ protein, loss of neurological function and even a decreased number of nerves (8-10).

Serum $A \beta$ is important in the onset of Alzheimer's disease, and aggregation of serum $A \beta$ and neurofibrillary tangle are major pathological changes of the disease. Aggregation of serum $A \beta$ can increase oxygen-free radicals and elevate the level of pro-inflammatory cytokines, resulting in apoptosis and degenerative changes in the nervous system (11-13). The drug donepezil has a long-term therapeutic effect on Alzheimer's disease, which has been recognized by the medical community. As a member of the second generation of cholinesterase inhibitors, donepezil can reversibly inhibit the hydrolysis of acetylcholine caused by acetylcholinesterase and increase the content of acetylcholine in cerebral cortex, in order to ameliorate the cognitive ability of the patients. Furthermore, donepezil has fewer adverse reactions, milder symptoms and higher safety (14-17). In the present study, the MMSE and MoCA scores after treatment in the two groups were significantly increased $(\mathrm{P}<0.05)$, and the ADL score was decreased significantly $(\mathrm{P}<0.05)$. Compared with the control group, the MMSE and MoCA scores in the experimental group were higher $(\mathrm{P}<0.05)$ while the ADL score was decreased $(\mathrm{P}<0.05)$, and the adverse reaction rate during the treatment was lower $(\mathrm{P}<0.05)$. The $\mathrm{A} \beta$ levels in serum after medical treatment were obviously decreased in the two groups $(\mathrm{P}<0.05)$. The serum $A \beta$ levels in the experimental group after treatment was lower than that in the control group $(\mathrm{P}<0.05)$. The results of the present study indicate that donepezil can improve the nerve conduction function and enhance information transmission in the brain by inhibiting the hydrolysis of acetylcholine and aggregation of $A \beta$, thus ameliorating patients' cognitive ability, memory and activities of daily living (18-20).

In conclusion, drug therapy combined with donepezil has a certain degree of influence on the MMSE, ADL and MoCA scores of patients with Alzheimer's disease. Donepezil can decrease the $A \beta$ level in peripheral blood and improve the cognitive functions of patients, thus having important clinical significance.

\section{References}

1. Sun HQ, Zhang X, Huang WJ and Chen WW: The news advances on Alzheimer's disease's therapeutics. Eur Rev Med Pharmacol Sci 20: 1903-1910, 2016.

2. Singh S, Kushwah AS, Singh R, Farswan M and Kaur R: Current therapeutic strategy in Alzheimer's disease. Eur Rev Med Pharmacol Sci 16: 1651-1664, 2012.

3. Zhang B, Gaiteri C, Bodea LG, Wang Z, McElwee J, Podtelezhnikov AA, Zhang C, Xie T, Tran L, Dobrin R, et al: Integrated systems approach identifies genetic nodes and networks in late-onset Alzheimer's disease. Cell 153: 707-720, 2013.

4. Lu JX, Qiang W, Yau WM, Schwieters CD, Meredith SC and Tycko R: Molecular structure of $\beta$-amyloid fibrils in Alzheimer's disease brain tissue. Cell 154: 1257-1268, 2013.

5. Stammberger HR and Kennedy DW; Anatomic Terminology Group: Paranasal sinuses:anatomic terminology and nomenclature. Ann Otol Rhinol Laryngol Suppl 167: 7-16, 1995.

6. Wormald PJ: The agger nasi cell: The key to understanding the anatomy of the frontal recess. Otolaryngol Head Neck Surg 129: 497-507, 2003.

7. Fujikawa T, Takahashi T, Kinoshita A, Kajiyama H, Kurata A, Yamashita $\mathrm{H}$ and Yamawaki S: Quetiapine treatment for behavioral and psychological symptoms in patients with senile dementia of Alzheimer type. Neuropsychobiology 49: 201-204, 2004.

8. Katz I, de Deyn PP, Mintzer J, Greenspan A, Zhu Y and Brodaty $\mathrm{H}$ : The efficacy and safety of risperidone in the treatment of psychosis of Alzheimer's disease and mixed dementia: A meta-analysis of 4 placebo-controlled clinical trials. Int J Geriatr Psychiatry 22: 475-484, 2007. 
9. Tabit CE, Chung WB, Hamburg NM and Vita JA: Endothelial dysfunction in diabetes mellitus: Molecular mechanisms and clinical implications. Rev Endocr Metab Disord 11: 61-74, 2010.

10. Endemann DH and Schiffrin EL: Endothelial dysfunction. J Am Soc Nephrol 15: 1983-1992, 2004.

11. Izzard AS, Rizzoni D, Agabiti-Rosei E and Heagerty AM: Small artery structure and hypertension: Adaptive changes and target organ damage. J Hypertens 23: 247-250, 2005.

12. Zhang Y, Li W, Yan T, Lu C, Zhou X and Huang Y: Early detection of lesions of dorsal artery of foot in patients with type 2 diabetes mellitus by high-frequency ultrasonography. J Huazhong Univ Sci Technolog Med Sci 29: 387-390, 2009.

13. Nicolls MR, Haskins K and Flores SC: Oxidant stress, immune dysregulation, and vascular function in type I diabetes. Antioxid Redox Signal 9: 879-889, 2007.

14. Gokce N, Vita JA, McDonnell M, Forse AR, Istfan N, Stoeckl M, Lipinska I, Keaney JF Jr and Apovian CM: Effect of medical and surgical weight loss on endothelial vasomotor function in obese patients. Am J Cardiol 95: 266-268, 2005.

15. Lteif AA, Han K and Mather KJ: Obesity, insulin resistance, and the metabolic syndrome: Determinants of endothelial dysfunction in whites and blacks. Circulation 112: 32-38, 2005.
16. Mwangi IW, Ngila JC, Ndungu P and Msagati TA: Method development for the determination of diallyldimethylammonium chloride at trace levels by epoxidation process. Water Air Soil Pollut 224: 1638, 2013.

17. Shams PN and Foster PJ: Clinical outcomes after lens extraction for visually significant cataract in eyes with primary angle closure. J Glaucoma 21: 545-550, 2012.

18. Foley RN, Parfrey PS and Sarnak MJ: Epidemiology of cardiovascular disease in chronic renal disease. J Am Soc Nephrol 9 (Suppl): S16-S23, 1998.

19. Malyszko J: Mechanism of endothelial dysfunction in chronic kidney disease. Clin Chim Acta 411: 1412-1420, 2010.

20. Izumi S, Muano T, Mori A, Kika G and Okuwaki S: Common carotid artery stiffness, cardiovascular function and lipid metabolism after menopause. Life Sci 78: 1696-1701, 2006.

(i) (9) This work is licensed under a Creative Commons Attribution-NonCommercial-NoDerivatives 4.0 International (CC BY-NC-ND 4.0) License. 